Vol. 23, No. 4, pp. 339 349, 2020.

\title{
The basics of electrode material evaluation in (photo)electrochemical system
}

\section{Sang Gu Ji and Chang Hyuck Choi ${ }^{\dagger}$}

School of Materials Science and Engineering, Gwangju Institute of Science and Technology, 123 Cheomdangwagi-ro, Buk-gu, Gwangju 61005, Republic of Korea

\section{(광)전기화학 시스템 전극 재료 분석의 기초}

\author{
지상구, 최창혁 ${ }^{\dagger}$ \\ 광주과학기술원 신소재공학부
}

(Received November 16, 2020; Revised December 7, 2020; Accepted December 8, 2020)

\begin{abstract}
s
Investigation of the targeted electrode in (photo)electrochemical system is typically carried out in a conventional three-electrode system, which is comprised of working, counter, and reference electrodes in a batch-type electrochemical reactor. Depending on the nature of targeted electrode, appropriate use of the counter electrode, which balances the charge transfers from the working electrode, is recommended to avoid any contaminations. However, this analytical basic has been often ignored, producing non-negligible but incognizant artifact in experimental results and finally leading to a failure in their correct interpretations. Herein, we highlight the importance of selection on counter electrode and cell configuration for achieving the best practice of (photo)electrochemical investigations with two different model systems, i.e., photoelectrochemical hydrogen evolution reaction (HER) on a $\mathrm{p}-\mathrm{Si}$ photocathode and electrochemical oxygen reduction reaction (ORR) on a polycrystalline platinum. From the model studies, we further discuss about the suitable electrochemical systems for accurate measurements of (photo)electrode materials.
\end{abstract}

Keywords: Pt dissolution, AgCl leaching, graphite counter electrode, carbon monoxide, poisoning

${ }^{\dagger}$ Corresponding Author: Chang Hyuck Choi

E-mail: chchoi@gist.ac.kr 

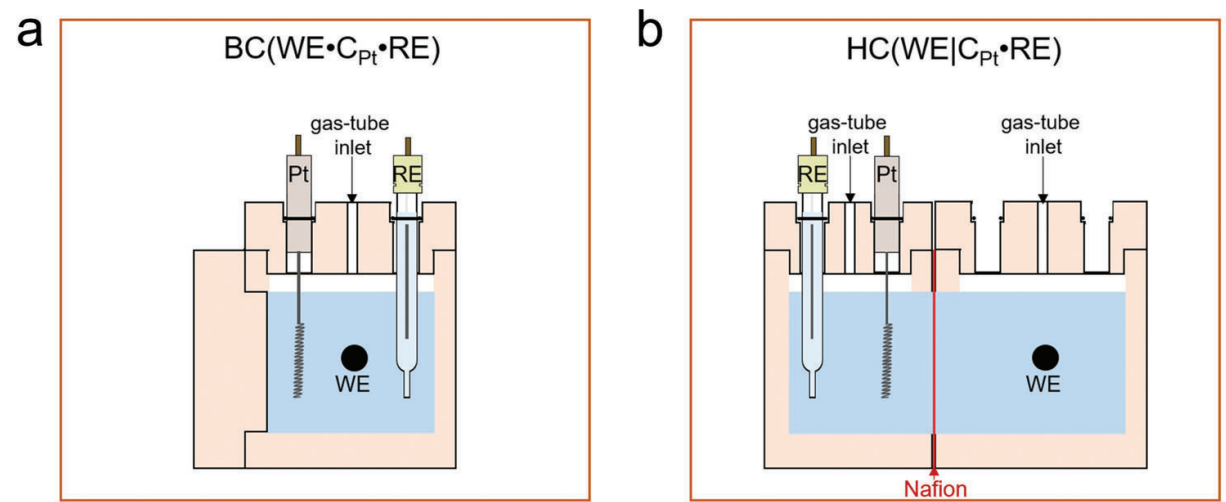

Fig. 1. (a) Batch-type cell 그리고 (b) H-type cell의 도식 이미지.7) Reprinted(adapted) with permission from (ACS Catal. 2020, 10, 5, 3381 -3389). Copyright (2020) American Chemical Society.

\section{1. 서론}

전기촉매작용은 전극/전해질 계면의 물리화학적 이 해를 바탕으로 연구가 진행된다. 이를 위한 전극 물질 의 정밀한 전압 전류 반응 분석은 일반적으로 작업전 극, 상대전극 그리고 기준전극으로 구성 된 3 전극 반 응기에서 이뤄진다. ${ }^{1)}$ 전극셀에세는 전류가 작업전극 과 상대전극 사이에서 흐르고, 작업전극의 전위는 기 준전극을 기준으로 하여 전위조절기로 조절된다. 백금 $(\mathrm{Pt})$ 은 흔히 사용하는 상대전극으로, 다양한 전기화학 반응에서 높은 안정성과 활성을 띄기 때문이다. ${ }^{2-5)}$ 하 지만, 전기화학 반응 도중 $\mathrm{Pt}$ 상대전극의 용해/재퇴적 (dissolution/redeposition)으로 인해 작업전극의 고유 한 특성 평가의 어려움이 존재한다. ${ }^{2-7)}$ 따라서, 백금이 아닌 graphite을 상대전극으로 대체하여 활용하고 있지 만, 이에 대한 안정성 및 유효성에 대한 연구는 미미하 다. 또는, 작업전극에서 생성된 전류를 상쇄시키기 위해 높은 전압이 graphite 상대전극으로 유도되고, 이는 카 본이 열역학적으로 부식(corrosion)됨에 따라 일산화탄 소 $(\mathrm{CO})$ 혹은 이산화탄소 $\left(\mathrm{CO}_{2}\right)$ 가 생성될 수 있다. ${ }^{8.9)}$ 중 간체인 $\mathrm{CO}$ 는 금속 물질에 강하게 흡착하는 종으로 활성 점을 피독시킬 수 있는 것으로 알려져 있다. ${ }^{10,11)}$ 상대전 극뿐만 아니라 기준전극을 은/염화은 $(\mathrm{Ag} / \mathrm{AgCl})$ 으로 직 접 반응기에 이용할 경우 $\mathrm{AgCl}$ 염 형태로 반응기 내에 리칭(leaching)을 야기시킬 수 있기에 double junction
을 통한 $\mathrm{Ag}$ 불순물의 영향을 배제해야 한다. ${ }^{7,12)}$ 본론에 서는 (광)전기화학 시스템 내에서의 수소발생반응과 더 불어 산소환원반응을 기반으로 정밀한 특성 평가 시스 템의 타당성을 논의하였다.

\section{2. 광전기화학 시스템 내에서 수소 발생 반응 특성 평기}

광전기화학 시스템에서 전극 촉매의 정밀한 특성 평 가를 위해 H-type 혹은 batch-type cell 형태로 변환 가능한 반응기를 직접 제작하였다 (Fig. 1). 타당성 평가 를 위해 $\mathrm{Pt}$ 혹은 흑연(graphite) 전극을 필요에 따라 상 대전극으로 구성하였으며 $\mathrm{Ag} / \mathrm{AgCl}$ 을 기준전극으로 적 용했을 때, double junction 사용 여부에 따른 활성 변 화를 비교하였다. 가장 일반적으로 사용하는 batchtype cell에서 수소발생반응을 모델 반응으로 선정하여 활성 변화를 확인했다. Fig. 2는 작업전극, 상대전극 및 기준전극을 $\mathrm{p}-\mathrm{Si}$, 백금 와이어(Pt wire) 및 $\mathrm{Ag} / \mathrm{AgCl}$ 을 이용하여 수소발생반응 활성을 확인했다. 아르곤 $(\mathrm{Ar})$ 이 충분히 포화된 $0.5 \mathrm{M} \mathrm{H}_{2} \mathrm{SO}_{4}$ 전해질에서 선형주사전 위법(linear sweep voltammetry, LSV)을 통해 수소발 생반응 성능을 확인했다(Fig. 2 (a)). 빛이 조사된(light illumination) 조건에서 첫번째와 열번째의 LSV 스캔 을 비교해 본 결과, 전류밀도 값이 $-1 \mathrm{~mA} \mathrm{~cm}{ }^{-2}$ 에 도달 할 때 개시 전위(onset potential)는 대략 -0.37 그리 고 $-0.15 \mathrm{~V}_{\mathrm{RHE}}$ 로 수소발생반응 활성은 스캔 수가 증가 

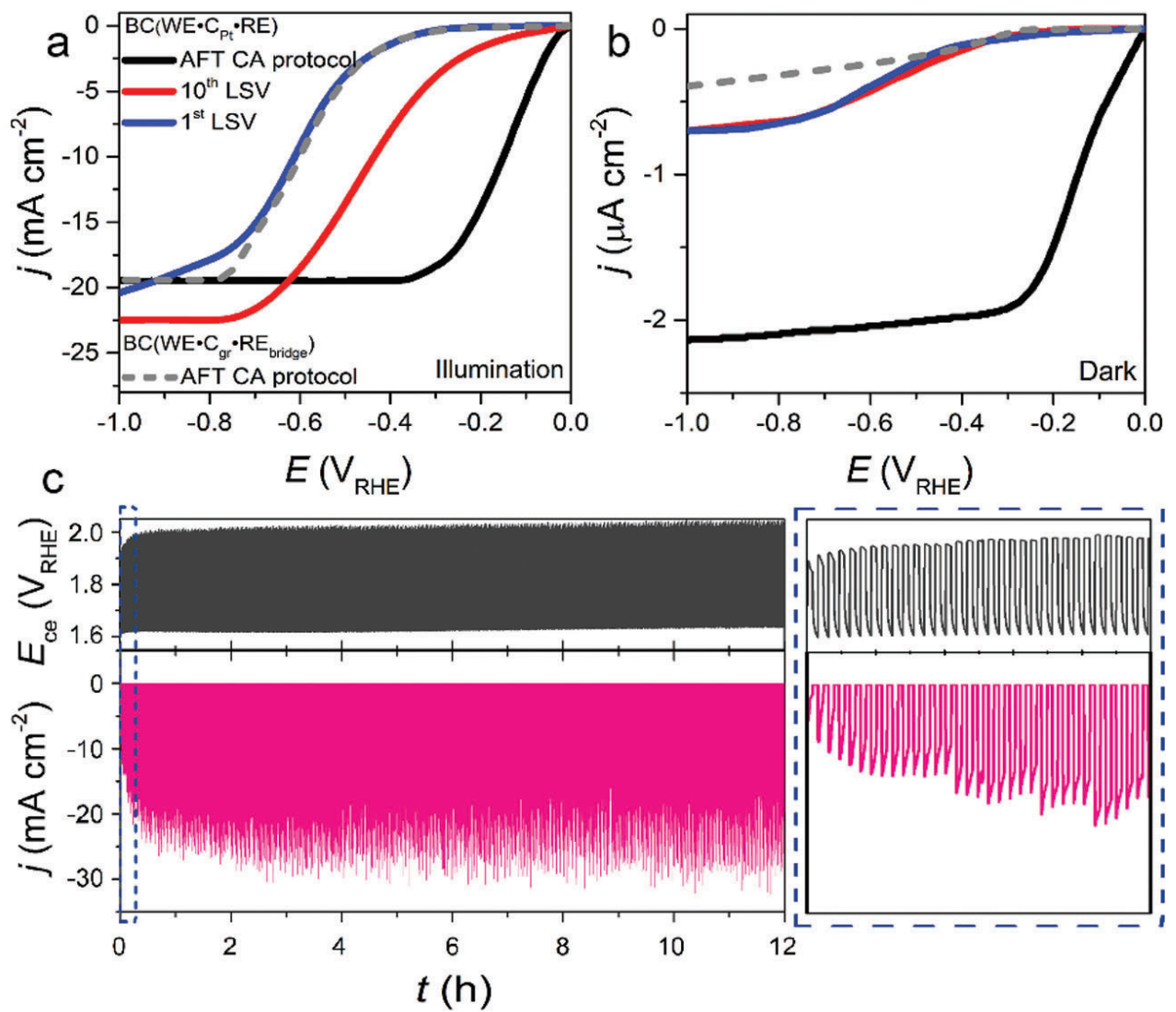

Fig. 2. (a) 빛이 조사된 조건과 (b) 없는 조건에서 p-Si의 수소발생반응 분극 곡선. (c) Light-on/off(15s each) illumination 조건에서 p-Si 의 안정성 평가(lower panel). 동시에 Pt 상대전극에 유도된 전압을 측정(upper panel). ${ }^{7)}$ Reprinted with permission from (ACS Catal. 2020, 10, 5, 3381-3389). Copyright (2020) American Chemical Society.

함에 따라 향상된 것을 확인했다. 또한 생성된 전류밀 도 값이 $-10 \mathrm{~mA} \mathrm{~cm}$ 을 기준으로 과전압을 비교한 결 과, 첫번째 LSV에 비해 대략 $170 \mathrm{mV}$ 감소를 보였다. 이와 같은 수소발생반응 활성 향상은 빛이 없는 조건에 서도 같은 경향성을 보이고 있다(Fig. 2 (b)). 이는, 비 교군으로 도입한 $\mathrm{BC}\left(\mathrm{WE} \cdot \mathrm{C}_{\mathrm{gr}} \cdot \mathrm{RE}_{\mathrm{bridge}}\right.$ )(graphite 상 대전극 및 double junction을 이용한 기준전극, 불순물 영향을 최대한 배제한 조건)과 비교했을때 비해 상대적 으로 높은 성능을 보이고 있다. 안정성 평가를 위해 시 간대전류법(chronoamperometry)을 총 12 시간에 걸쳐 light-on/off illumination을 $-0.6 \mathrm{~V}_{\mathrm{RHE}}$ 에서 진행했다 (Fig. 2 (c)). 시간이 지남에 따라, 전류밀도 값이 증가 하였고, 최대 $-28 \mathrm{~mA} \mathrm{~cm}$ 값에 도달했다. 이러한 결 과를 토대로, 전체적인 전압전류법(voltammetry)에
서 수소발생반응의 활성 증가를 확인했고, 이는 $\mathrm{Pt}$ 종 이 성능 증가를 야기시킨 것으로 추정된다. 원인을 확 인하기 위해 수소발생반응 중 $\mathrm{Pt}$ 상대전극에 자동적으 로 유도된 전압을 확인했다(작업전극에서 생성된 전류 를 상쇄하기 위해 자동적으로 전압이 조절된다). 이는 Fig. 2 (c)에서 총 12 시간의 안정성 평가 도중 대략 1.6$2.0 \mathrm{~V}_{\mathrm{RHE}}$ 구간에서 변동하고 있는 것을 확인했다. 이를 토대로, Pt의 dissolution을 확인하기 위해 상대전극 에 걸린 전압을 모방하여, online scanning flow cell 으로부터 장착된 inductively coupled plasma-mass spectrometry(online $\mathrm{SFC} / \mathrm{ICP}-\mathrm{MS}$ )를 도입했다(Fig. 3 (a), (b)), 전압이 규칙적으로 변화하는(실제 수소발 생반응 도중 상대전극에 유도된 전압)구간에서 Pt이 녹 는 것을 확인하였고, 이는 대략 $0.070 \mathrm{ng} \mathrm{cm}$ 정도이 


\section{특 집 ㅁㅃ 지상구, 최창혁}
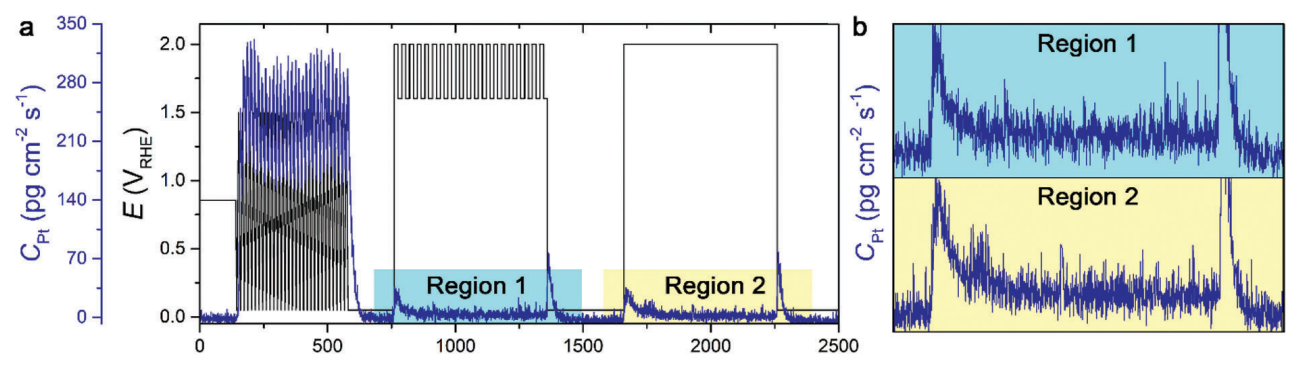

$t(\mathrm{~s})$

$t(\mathrm{~s})$
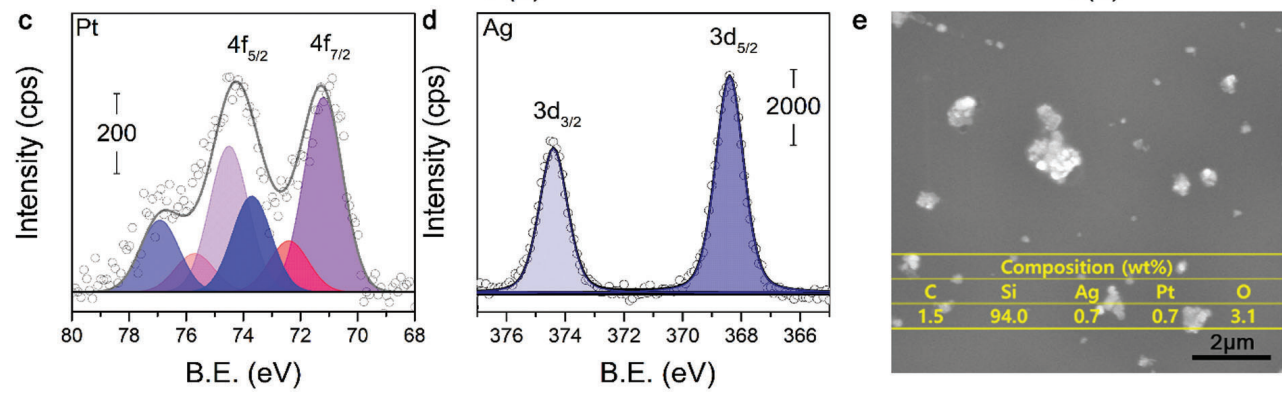

Fig. 3. (a) Online SFC/ICP-MS를 통해 전압에 따른 polycrystalline Pt 용해 도식화. (b) Region 1과 Region 2의 확대된 이미지. (c) XPS$\mathrm{Pt}_{4 f}$ 그리고 (d) $-\mathrm{Ag}_{3 \mathrm{~d}}$ spectra. (e) 안정성 평가 진행 후 측정한 $\mathrm{SEM}$ 이미지 및 $\mathrm{EDX}$ 로 확인한 중량 퍼센트.") Reprinted with permission from (ACS Catal. 2020, 10, 5, 3381-3389). Copyright (2020) American Chemical Society.

다(Region 1). 또한 지속적인 빛의 조사 조건을 모방하 기 위해, $2.0 \mathrm{~V}_{\mathrm{RHE}}$ 에서 정전압을 걸어줌에 따른 $\mathrm{Pt}$ 녹 는 정도를 확인했다(Region 2). Region 1과 유사하게 $\mathrm{Pt}$ 이 녹는 것을 확인했고, 그 양은 대략 $0.072 \mathrm{ng} \mathrm{cm}$-2 으로 정전압 및 전압이 변동하는 구간에서 $\mathrm{Pt}$ 가 용해 될 수 있음을 확인했다. 하지만, Pt가 용해됐더라도 실 제로 작업전극에 재퇴적이 가능한지에 대한 여부는 확 실치 않다. 따라서 $\mathrm{Pt}$ 의 용해/재퇴적 현상을 확인하 기 위해 엑스선광전자분광법(X-ray photoelectron spectroscopy, XPS) 및 주사전자현미경(Scanning electron microscopy, SEM) 그리고 에너지 분산형 X선 분광법(Energy-dispersive X-ray spectroscopy, $\mathrm{EDX})$ 을 통해 면밀히 분석했다. 앞서 안정성 평가를 진 행한 시료를 토대로 분석했고, 결과는 Fig. 3 (c), (d) 에 나타냈다. Fig. 3 (c)로부터 표시된 $\mathrm{Pt}_{4 \mathrm{f}}$ 스펙트럼 (spectrum)으로부터 3개의 전자 상태(electronic state) 인 $\mathrm{Pt}^{0}(71.2 \mathrm{eV}), \mathrm{Pt}^{2+}(72.4)$ 그리고 $\mathrm{Pt}^{4+}(73.7 \mathrm{eV})$ 로 확 인된다. 주요한 state는 $\mathrm{Pt}^{0}$ 으로 작업전극에 metallic한 $\mathrm{Pt}$ 형태로 재퇴적 될 수 있음을 확인했다. 놀랍게도, 작
업전극 표면에 $\mathrm{Ag}$ 의 재퇴적을 XPS $\mathrm{Ag}$ 스펙트럼으로 부터 확인했고, metallic한 $\mathrm{Ag}$ 형태로 존재한다(Fig. 3 (d)). 이를 토대로, 기준 전극인 $\mathrm{Ag} / \mathrm{AgCl}$ 를 직접 반응 기에 배치할 경우, $\mathrm{AgCl}$ 염 형태로 전해질에 용해/ 재 퇴적될 수 있음을 보여준다. 위 결과를 토대로, $\mathrm{Pt}$ 및 $\mathrm{Ag}$ 는 작업전극인 $\mathrm{p}-\mathrm{Si}$ 에 재퇴적 될 수 있음을 보여준 다. 이는 Fig. 3 (e)의 SEM 및 $\mathrm{EDX}$ 로부터 Pt, $\mathrm{Ag}$ 혹 은 $\mathrm{Pt}-\mathrm{Ag}$ 합금 형태로 작업전극 표면에 재퇴적됨을 확 인했다. 실험적 근거를 통해 $\mathrm{Pt}$ 그리고 $\mathrm{Ag}$ 가 재퇴적됨 에 따른 수소발생반응 활성 영향을 확인하기 위해 불순 물이 포함되어 있는 염(염화백금산(chloroplatinic acid) 및 질산은(silver nitrate))을 0.01-2 ppm 농도로 조 절하여 $\mathrm{Ar}$ 이 충분히 포화된 $0.5 \mathrm{M} \mathrm{H}_{2} \mathrm{SO}_{4}$ 전해질에 녹 여 앞서 진행한 $\mathrm{CA}$ protocol을 동일하게 측정했다. 또 한, Pt 대신 graphite을 상대전극으로 사용했고, 기준 전극에는 double junction을 사용하여 기존 시스템에서 $\mathrm{Pt}$ 혹은 $\mathrm{Ag}$ 의 용해/재퇴적 가능성을 배제하고자 하였 다. $\mathrm{Pt}$ 염이 0.01 부터 $2 \mathrm{ppm}$ 까지 증가할 때, 과전압이 (전류 밀도 값이 $10 \mathrm{~mA} \mathrm{~cm}$ 에 도달할 때 값) 530에서 

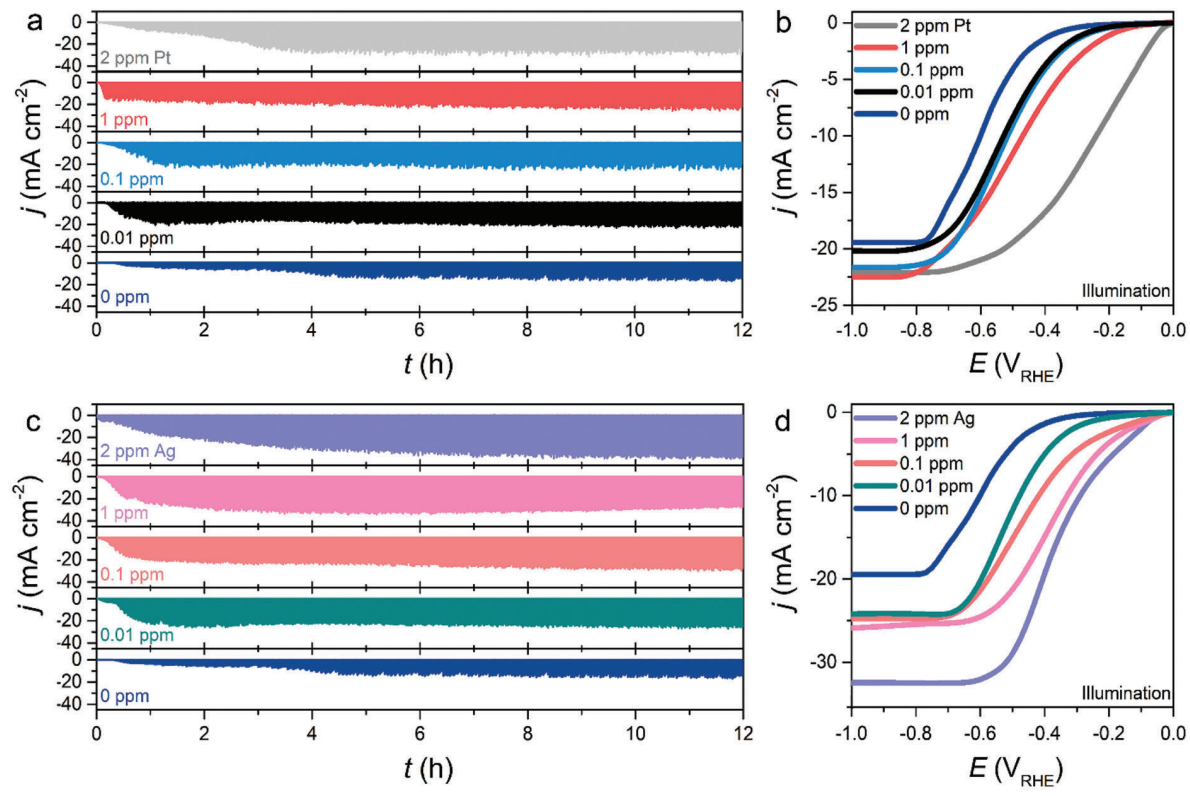

Fig. 4. 전해질 내 미량의 Pt (a and b) 그리고 $\mathrm{Ag}$ (c and d) 이온이 p-Si의 수소발생반응 활성에 미치는 영향. 0.01-2 ppm의 Pt (a) 그리 고 $\mathrm{Ag}(\mathrm{c})$ 이온이 존재할 때 안정성 평가. 안정성 평가 후, $\mathrm{Pt}(\mathrm{b})$ 그리고 $\mathrm{Ag}(\mathrm{d})$ 이온을 포함한 전해질에서 수소발생반응 분극 곡선. ${ }^{7)}$ Reprinted with permission from (ACS Catal. 2020, 10, 5, 3381-3389). Copyright (2020) American Chemical Society.

$240 \mathrm{mV}$ 까지 감소하는 것으로부터 활성 증가를 야기시 켰고, 이는 $\mathrm{Ag}$ 염 농도의 양이 증가함에 따라 과전압이 감소되는 현상을 확인했다(480에서 $290 \mathrm{mV}$ 로 감소). 이 결과를 토대로, 소량의 $\mathrm{Pt}$ 그리고 $\mathrm{Ag}$ 불순물은 무시 하지 못할 정도의 활성 향상을 야기시킬 수 있다. 이는 Chung group으로부터 $\mathrm{p}-\mathrm{Si}$ 에 $\mathrm{AgPt}$ 합금 나노 입자 (AgPt alloyed nanoparticles)를 갈바닉 교환(galvanic exchange) 방법으로 증착함에 따른 수소발생반응 활성 증가 경향성과 비슷한 효과를 보인다. ${ }^{13)}$ 위 그룹에서는 $\mathrm{Ag}$ 에서 $\mathrm{Pt}$ 로 수소 스필오버(hydrogen spillover) 효과 뿐만 아니라 Pt의 일함수(work function)을 완화시킴에 따른 효율적인 광전자 추출이 주요 원인이라 주장했다. 따라서, 광전기화학을 모델 시스템으로 $\mathrm{Pt}$ 상대전극과 $\mathrm{Ag} / \mathrm{AgCl}$ 기준전극을 이용했을 경우 금속 물질의 용해/ 재퇴적에 의한 수소발생반응의 활성 증가를 야기시킨다 는 것을 확인했다.

\section{Graphite 상대전극에 대한 적합성 평가}

$\mathrm{Pt}$ 는 화학적 내구성이 뛰어나고 훌륭한 전기전도체 물 질로 다양한 전기화학 반응에 상대전극으로 이용되고 있 다. 하지만, 정밀한 전기화학 특성 평가에 대한 적합성 에 대해서는 부정적인 영향을 야기시킬 수 있다고 보고 된 바 있다. 이는 특정 조건에서 Pt는 열역학적으로 이온 형태로 용해될 수 있고 재퇴적됨에 따라 활성 평가에 상 당한 영향을 미친다. ${ }^{2-7)}$ 이와 같은 이유로 graphite 상대 전극을 대체제로 사용하고 있다. 하지만, graphite을 상 대전극으로 이용했을 경우, 정밀한 전기화학 특성 평가 에 적합한지에 대한 의구심이 생긴다. 카본(carbon) 물 질은 열역학적으로 $\mathrm{E}^{0}=0.207 \mathrm{~V}_{\mathrm{RHE}}$ 이상부터 부식됨에 따라 $\mathrm{CO}_{2}$ 를 발생시킬 수 있고 $\mathrm{E}^{0}=0.518 \mathrm{~V}_{\mathrm{RHE}}$ 이상부 터는 중간 생성물인 $\mathrm{CO}$ 를 생성할 수 있기 때문이다. ${ }^{14,15)}$ $\mathrm{CO}$ 는 다양한 금속과 강한 결합 친화성을 갖고 있고 기 존의 카본을 지지체로 이용한 $\mathrm{Pt} / \mathrm{C}$ 그리고 단원자 촉매 인 $\mathrm{Fe}-\mathrm{N}-\mathrm{C}$ 는 $1.2 \mathrm{~V}_{\mathrm{RHE}}$ 이상의 전압을 가했을 때, $\mathrm{CO}$ 가 생성될 수 있음을 보고했다. ${ }^{16-18)}$ Graphite 상대전극을 

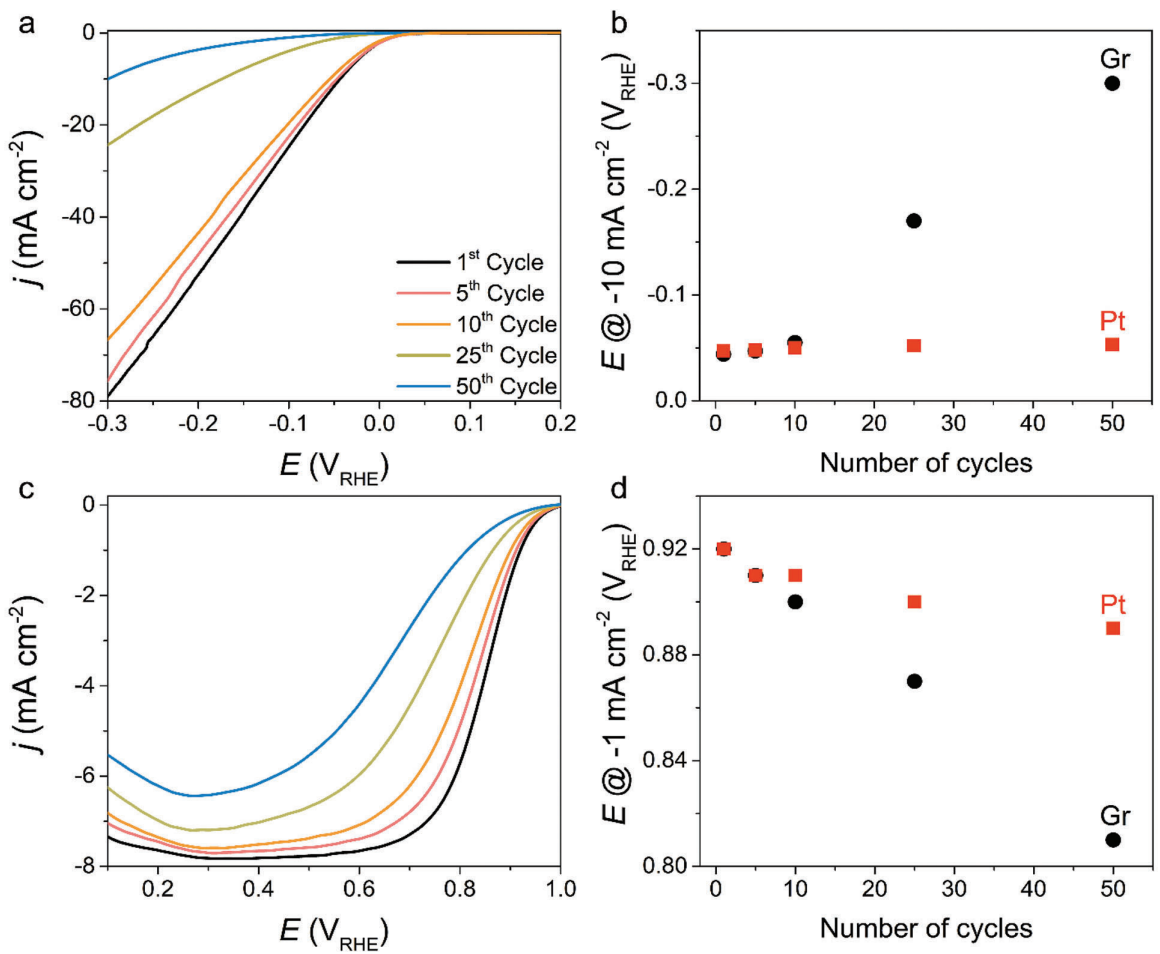

Fig. 5. (a) Graphite 상대전극을 이용한 polycrystalline Pt의 수소발생 및 (c) 산소환원반응 분극 곡선. 생성된 전류 밀도가 (b) $-10 \mathrm{~mA} \mathrm{~cm}-2$ (수소발생반응) 그리고 (d) $-1 \mathrm{~mA} \mathrm{~cm}$ (산소환원반응)일 때 측정한 과전압 및 사이클수의 상관관계. ${ }^{19)}$ Reprinted with permission from (ACS Catal. 2020, 10, 18, 10773-10783). Copyright (2020) American Chemical Society.

이용할 경우, 금속의 부재로 인해 카본 부식은 다른 반응 경로 혹은 높은 과전압이 걸릴 것으로 예상한다. 하지만, 상대전극은 작업전극으로부터 생성된 전류를 상쇄시키 기 위해 자동적으로 전압이 조절되는데, 일반적으로 많 은 환원 전류가 발생될 경우, 상대전극에서는 높은 전압 이 유도됨에 따라 $\mathrm{CO}_{2}$ 혹은 $\mathrm{CO}$ 가 생성될 수 있는 사실 을 무시하지 못한다. ${ }^{19)}$ 본론에서는 graphite를 상대전극 으로 이용하였을 때, 전기화학촉매작용에 적합한지 평가 했다.

\section{4. $\mathrm{Pt}$ 작업전극을 기반한 3 전극셀에서 수소발생 및 산소환원반응 활성 평가}

Graphite 상대전극 사용에 대한 타당성을 확인하 기 위해 모델 촉매인 polycrystalline $\mathrm{Pt}$ 를 작업전극으 로 이용하여 수소발생 및 산소환원반응 활성을 평가했
다. $\mathrm{Ar}$ 이 충분히 포화된 $0.1 \mathrm{M} \mathrm{HClO}_{4}$ 전해질에서 총 50 사이클의 순환전압전류법(cyclic voltammetry)을 통해 수소발생반응을 평가했다(Fig. 5 (a)). 전체적으 로 사이클수가 증가함에 따라 활성이 감소하는 것을 확 인했고, 이는 생성된 전류 밀도 값이 $10 \mathrm{~mA} \mathrm{~cm}$ 일 때 의 과전압을 비교해 본 결과(Fig. 5 (b)), 첫번째 사이클 에 비해 50 번째 사이클에서 $256 \mathrm{mV}$ 만큼 증가한 과전 압을 확인했다. 또한, $\mathrm{Pt}$ 를 상대전극으로 사용했을 경 우에는 $6 \mathrm{mV}$ 만큼의 과전압 증가를 확인했을 때, 상당 한 활성 감소를 야기시켰다. 비슷한 경향성은 총 50 사 이클의 $\mathrm{CV}$ 를 이용하여 산소환원반응 활성을 측정했을 때도 확인할 수 있었다(Fig. 5 (c)). 첫번째 스캔에서는 polycrystalline Pt의 onset potential 및 확산 전류 밀 도(diffusion current density) 값이 대략 $1 \mathrm{~V}_{\mathrm{RHE}}$ 및 -8 $\mathrm{mA} \mathrm{cm}{ }^{-2}$ 으로 4 전자 반응 경로에 인한 산소를 물로 환 원시키는 반응이 주요한 것을 확인하였다. 하지만 사이 
a

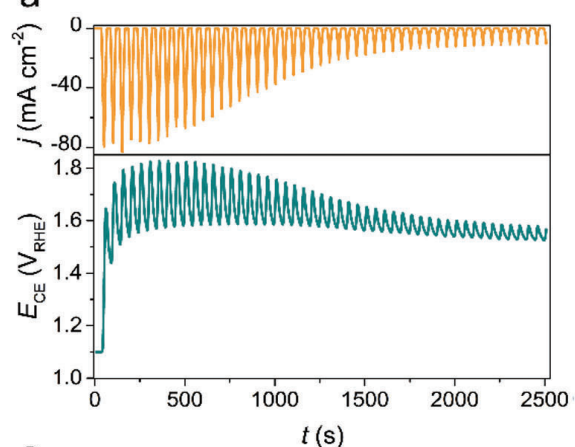

C

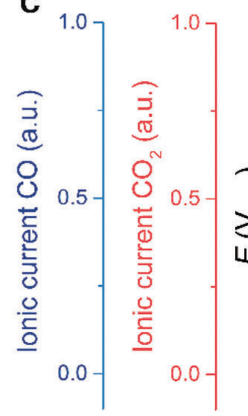

b

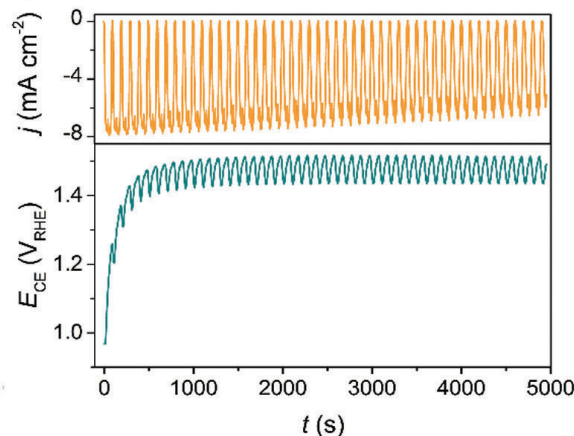

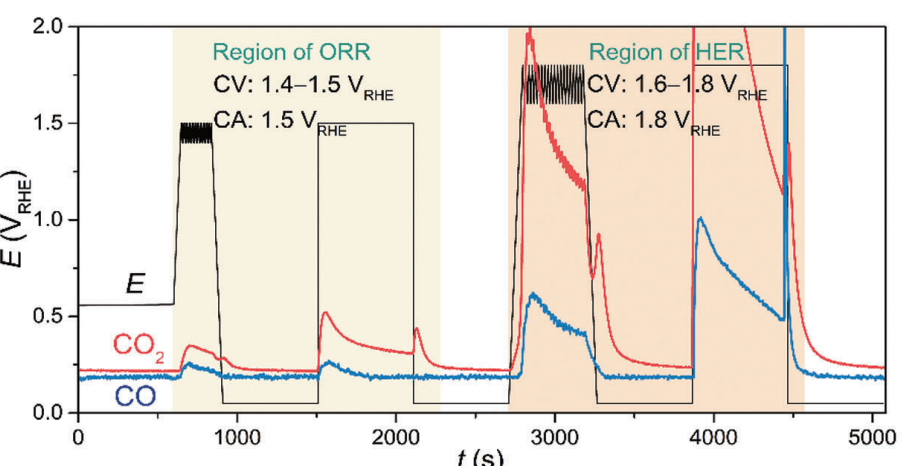

$t$ (s)

Fig. 6. 50 사이클의 (a) 수소발생 및 (b) 산소환원반응 동안 polycrystalline Pt의 측정된 전류 밀도(upper panel) 및 동시에 graphite 상대 전극에 유도된 전압(lower panel). 다공성 carbon black(Vulcan XC 72R)을 모델 촉매로, 실시간 전기화학 반응 도중 생성된 CO 및 $\mathrm{CO}_{2}$ 를 online DEMS을 이용하여 확인.' ${ }^{19)}$ Reprinted with permission from (ACS Catal. 2020, 10, 18, 10773-10783). Copyright (2020) American Chemical Society.

클 수가 증가함에 따라 onset potential 그리고 확산 조 절 영역(diffusion-controlled regions)에서의 전류 밀 도가 감소함에 따라 반응 경로가 4 전자에서 2 전자로 바뀌는 것으로 확인됐다. 더 면밀한 비교를 위해 사이 클 수에 따라 생성된 전류밀도 값이 $-1 \mathrm{~mA} \mathrm{~cm}{ }^{-2}$ 일 때 의 과전압을 도표했다(Fig. 5 (d)). 첫번재와 50 번째의 스캔을 비교했을 때, $110 \mathrm{mV}$ 의 과전압 증가를 보였고, 이는 $\mathrm{Pt}$ 상대전극을 사용했을 때(30 mV 증가)보다 심 화된 비활성화를 야기시켰다. 수소발생 및 산소환원반 응 도중 Pt 전극의 빠른 비활성화 원인을 규명하기 위 해 우선적으로 graphite 상대전극에 유도된 전압을 확 인했다(Fig. 6 (a), (b)). 수소발생반응 중 graphite 상 대전극에 걸린 전압은 $1.6-1.8 \mathrm{~V}_{\mathrm{RHE}}$ 범위 내에서 동적으 로 진동했고, 상대적으로 낮은 전류 밀도를 생성한 산 소환원반응에서는 $1.4-1.5 \mathrm{~V}_{\mathrm{RHE}}$ 범위 내에서 전압이 변 동하였다. 해당하는 전압 범위 내에서는 graphite 상
대전극은 충분히 카본 부식에 의해 $\mathrm{CO}$ 및 $\mathrm{CO}_{2}$ 를 생 성할 수 있으며, 이는 금속/carbon 기반 촉매 및 고 온에서 일어날 수 있음을 보고했다. 하지만, 본고에서 는 상온 조건 및 금속 components가 없기 때문에, 급 격한 활성 감소 원인을 설명하기에는 부족하다. 따라 서 실시간 전기화학 반응 도중 생성된 휘발성 물질을 분석할 수 있는 online differential electrochemical mass spectrometry(DEMS)를 통해 $\mathrm{CO}(\mathrm{m} / z=28)$ 혹은 $\mathrm{CO}_{2}(\mathrm{~m} / \mathrm{z}=44)$ 의 생성 여부를 확인했다(Fig. 6 (c)). DEMS 시그널을 향상시키기 위해 다공성 carbon black(Vulcan XC 72R)을 사용했다. 부식 경향성은 수 소생성 및 산소환원반응 중 graphite 상대전극에 유도 된 전압을 모방하여 전압이 지속적으로 변동한 조건과 정전압 조건에서 확인했다. 'ORR region'에서 총 $20 \mathrm{CV}$ 사이클을 진행함에 따라 발생한 $\mathrm{CO}_{2}$ 및 $\mathrm{CO}$ 의 질량 시 그널(mass signal)을 확인했고, 'HER region'에서는 상 

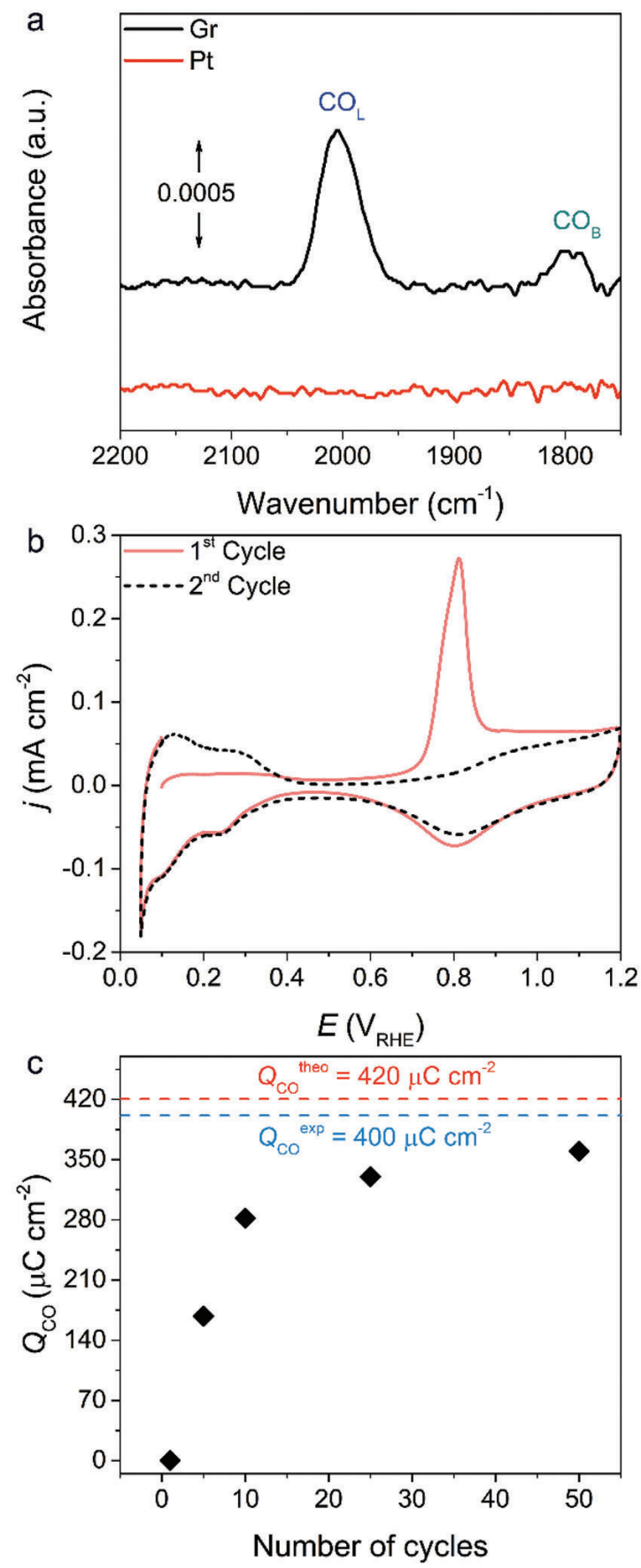

Fig. 7. (a) Polycrystalline Pt의 수소발생반응 측정 후 확인한 in situ ATR-SEIRAS spectra 및 (b) CO-stripping cyclic voltammetry. (c) 수소발생반응 사이클 수와 $\mathrm{CO}$ 흡착량의 상관관계. ${ }^{19)}$ Reprinted with permission from (ACS Catal. 2020, 10, 18, 10773-10783). Copyright (2020) American Chemical Society.
대적으로 더 향상된 질량 시그널을 확인했다. 이 결과를 토대로 수소생성 및 산소환원반응 중 급격한 활성 감소 의 원인은 $\mathrm{CO}$ 라고 추측된다. 이는 $\mathrm{Pt}$ 랑 강한 결합 친화 성(binding affinity)를 갖는 $\mathrm{CO}$ 는 활성점을 피독시킬 수 있기 때문이다. 하지만, 이 결과만으로 비활성화 향 상에 대한 이유를 설명하기에는 불충분하다. $\mathrm{CO}$ 가 생성 되었다 하더라도, 활성을 감소시키기에 충분한 농도인 지에 대한 의문 때문이다. 따라서, 강한 결합력을 갖는 $\mathrm{CO}$ 가 Pt 전극의 흡착 여부를 확인하기 위해 graphite 를 상대전극으로 이용하여 in situ attenuated total reflection surface-enhanced infrared absorption spectroscopy(ATR-SEIRAS)를 도입했다(Fig. 7 (a)). 수소발생반응에 적용한 실험 절차를 이용하여 확인해 본 결과, $\mathrm{Pt}$ 표면에 $\mathrm{CO}$ 는 linear 그리고 bridge 형태로 흡착된 것을 확인했다. 반면, $\mathrm{Pt}$ 를 상대전극으로 바꿔 확인해 본 결과, 어떠한 시그널도 관찰되지 않았다. 또 한, 총 50 사이클의 수소발생반응 후, electrochemical stripping 방법을 통해 CO 피독 효과를 더 면밀히 확인 했다(Fig 7 (b)). 첫번째 스캔(0.05-1.2 $\left.\mathrm{V}_{\mathrm{RHE}}\right)$ 에서는 Pt 의 $\mathrm{CV}$ 특성이 보이지 않았고, 대략 $0.8 \mathrm{~V}_{\mathrm{RHE}}$ 에서 강한 산화 픽을 확인했다. 두번째 스캔에서는 Pt 전극의 본래 전기화학적 특성이 회복되는 것을 확인함에 따라, 전형 적인 CO-stripping 결과와 거의 일치하는 모습을 보인 다. 이에 따라, online DEMS, in situ ATR-SEIRAS 그리고 CV 결과로부터, graphite 상대전극을 사용할 경 우, $\mathrm{CO}$ 의 생성/피독에 의해 $\mathrm{Pt}$ 전기화학촉매작용의 활 성 감소를 야기시킨다. CV 사이클 수의 증가에 따른 피 독 경향성을 전하 밀도로 계산해 볼 결과, 50 사이클의 수소발생반응 측정 후, 대략 $360 \mu \mathrm{C} \mathrm{cm}{ }^{-2}$ 의 전하 밀도 가 축적되어 있다(Fig. 7 (c)). 이는 polycrystalline Pt 에 이론적인 흡착 값인 $420 \mathrm{uC} \mathrm{cm}$ 에 근접한 값으로 대부분의 활성점을 피독시킨 결과로 보인다. ${ }^{20)}$ 산소환 원반응 평가 후 stripping voltammogram에서는 $\mathrm{CO}$ 의 산화 픽이 관찰되지 않았는데, 이는 산소환원반응의 전압 범위가 $\mathrm{CO}$ 가 산화되는 영역과 중복됨에 따라 경 쟁 반응으로 일어났을 것이라고 추측한다. 또한, 수소 발생반응 조건과 비교했을 때, 비활성화 정도가 완화되 

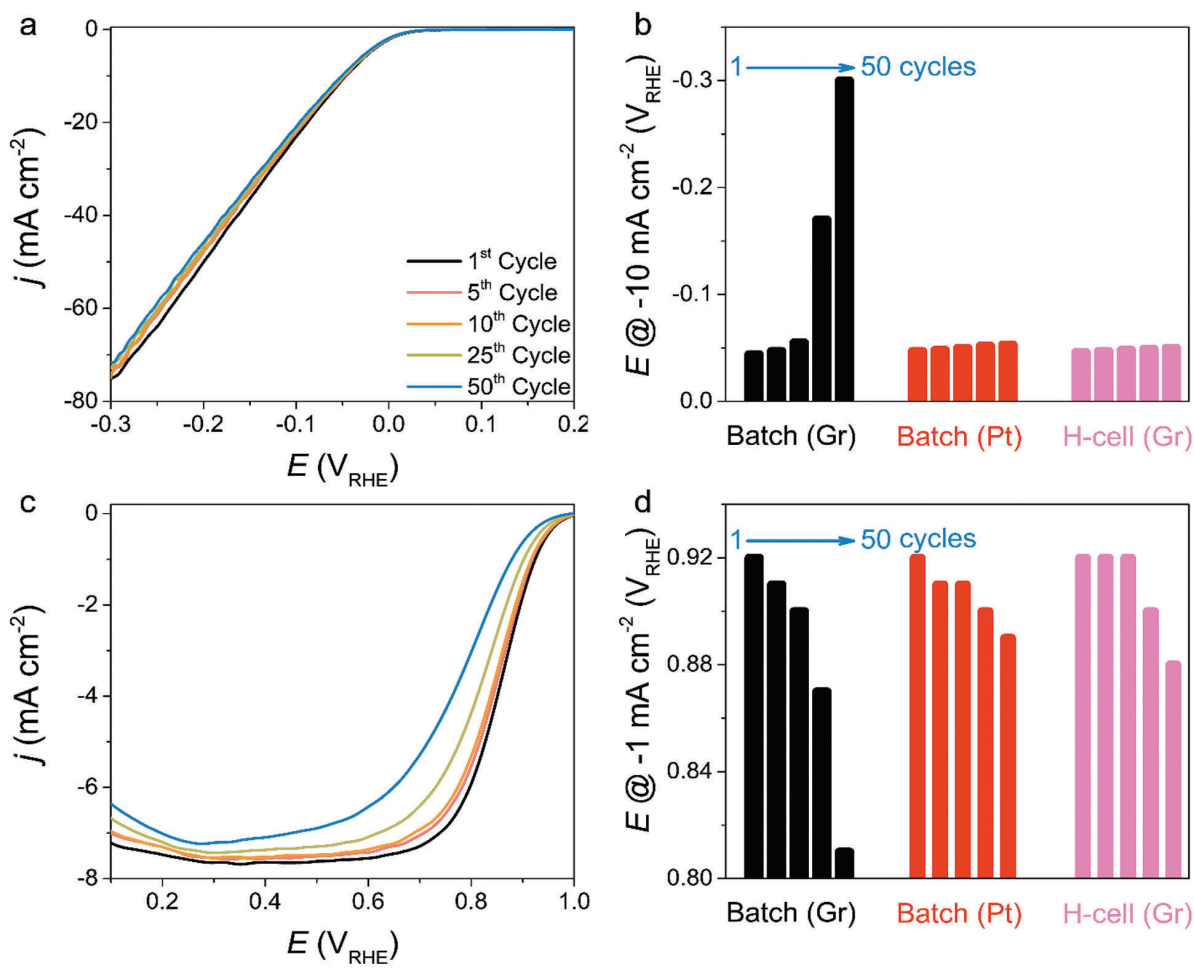

Fig. 8. H-type cell을 이용한 polycrystalline Pt의 (a) 수소발생 및 (c) 산소환원반응 활성 측정. Graphite 상대전극은 nafion 멤브레인을 통 해 분리. Batch type 및 H-type cell에서 측정한 전류 밀도가 (b) $-10 \mathrm{~mA} \mathrm{~cm}$ (수소발생반응) 그리고 (d) $-1 \mathrm{~mA} \mathrm{~cm}$ (산소환원반 응)의 과전압 비교. 비교를 위해 Pt 상대전극이 배치되어 있는 batch type cell 이용('Batch (Pt)).9. Reprinted with permission from (ACS Catal. 2020, 10, 18, 10773-10783). Copyright (2020) American Chemical Society.

었고, online DEMS로부터 생성된 $\mathrm{CO}$ 의 양이 상대적 으로 적었기 때문에 상대적으로 낮은 비활성화 정도를 야기시킨것으로 추정한다. $\mathrm{CO}$ 피독에 대한 영향을 배 제하기 위해 직접 제작한 $\mathrm{H}$-type cell을 적용하여 활 성 변화를 비교했다. Catholyte과 anolyte를 분리시키 기 위해 양성자 전도성 고분자막인 nafion을 도입하여 graphite 상대전극과 polycrystalline $\mathrm{Pt}$ 를 분리하였 다. Batch-type cell을 이용하여 수소발생반응을 측정 했을 때 비해 과전압 증가는 대략 $4 \mathrm{mV}$ 로 상당히 미미 한 활성 변화를 보인다(Fig. 8 (a), (b)). 이러한 경향성 은 총 50 사이클의 산소환원반응 측정 후 비교한 과전압 으로부터 유사하게 보이고, 대략 $40 \mathrm{mV}$ 증가를 야기시 켰다(Fig. 8 (c), (d)), 과전압 증가 정도는 Pt를 상대전 극으로 이용하여 batch-type cell에서 측정한 수소발생 및 산소환원반응 조건과 유사하다. 이에 따라, H-type cell을 사용했을 때의 활성 감소 요인은 다른 실험적 조 건들(e.g., halide 음이온들부터 poisoning 야기)로부 터 발생한 것으로 추정된다. 산 분위기에서 graphite 상대전극을 사용할 경우, 수소발생 및 산소환원반응 중 polycrystalline Pt 전극이 오염될 수 있는 사실을 입증 했다.

\section{5. 결론}

본론에서는 (광)전기화학 시스템을 모델로 3전극 시 스템 내에서 상대전극 및 기준전극의 타당성을 평가했 다. 광전기화학 시스템내에서 $\mathrm{Pt}$ 그리고 $\mathrm{Ag} / \mathrm{AgCl}$ 를 batch-type cell에 적용할 경우, 용해/재퇴적 현상에 의해 수소발생반응 성능이 과대평가될 수 있음을 보여 줬다. 또한, 전기화학 시스템에서는 graphite 상대전극 
으로 대체할 경우, 생성된 $\mathrm{CO}$ 가 $\mathrm{Pt}$ 활성점을 피독시켜 전기촉매작용에 상당한 과소평가를 미칠 수 있음을 입 증했다. ${ }^{21)}$ 본 연구의 결과로부터, 촉매 표면에 오염될 수 있는 원인을 방지하기 위해서는 세심한 주의를 기울여 평가하고자 하는 시스템을 설계하는 것이 중요하다. 작 업전극, 전기화학반응, 전위창 범위를 고려하여 적절한 상대전극을 선택하는 것을 추천한다.

\section{REFERENCES}

1. Bard, A. J.; Faulkner, L. R., Fundamentals and Applications. Electrochemical Methods, p 482, Wiley, 2001.

2. Chen, J. G.; Jones, C. W.; Linic, S.; Stamenkovic, V. R, "Best Practices in Pursuit of Topics in Heterogeneous Electrocatalysis" ACS Catal., 7 [18] 6392-6393 (2017).

3. Chen, R.; Yang, C.; Cai, W.; Wang, H.-Y.; Miao, J.; Zhang, L.; Chen, S.; Liu, B., Use of Platinum as the Counter Electrode to Study the Activity of Nonprecious Metal Catalysts for the Hydrogen Evolution Reaction. ACS Energy Lett., 2 [5] 1070-1075 (2017).

4. Wei, R.; Fang, M.; Dong, G.; Ho, J. C., Is Platinum a Suitable Counter Electrode Material for Electrochemical Hydrogen Evolution Reaction? Sci. Bull., 62 [14] 971-973 (2017).

5. Dong, G.; Fang, M.; Wang, H.; Yip, S.; Cheung, H.-Y.; Wang, F.; Wong, C.-Y.; Chu, S. T.; Ho, J. C., Insight into the Electrochemical Activation of Carbon-Based Cathodes for Hydrogen Evolution Reaction. J. Mater. Chem. A, 3 [24] 13080-13086 (2015).

6. Gottlieb, E.; Kopec, M.; Banerjee, M.; Mohin, J.; Yaron, D.; Matyjaszewski, K.; Kowalewski, T., In-Situ Platinum Deposition on Nitrogen-doped Carbon Films as a Source of Catalytic Activity in a Hydrogen Evolution Reaction. ACS Appl. Mater. Interfaces., 8 [33] 21531-21538 (2016).

7. Ji, S. G.; Kim, H.; Choi, H.; Lee, S.; Choi, C. H, Overestimation of Photoelectrochemical Hydrogen Evolution Reactivity Induced by Noble Metal Impurities Dissolved from Counter/Reference Electrodes. ACS Catal., 10 [5] 3381-3389 (2020).
8. Qiao, M.-X.; Zhang, Y.; Zhai, L.-F.; Sun, M., Corrosion of Graphite Electrode in Electrochemical Advanced Oxidation Processes: Degradation Protocol and Environmental Implication. Chem. Eng. J., 344 410418 (2018).

9. Maass, S.; Finsterwalder, F.; Frank, G.; Hartmann, R.; Merten, C., Carbon Support Oxidation in PEM Fuel Cell Cathodes. J. Power Sources, 176 [2] 444-451 (2008).

10. Baschuk, J.; Li, X., Carbon Monoxide Poisoning of Proton Exchange Membrane Fuel Cells. Int. J. Hydrog. Energy, 25 [8] 695-713 (2001).

11. Zheng, J.; Sheng, W.; Zhuang, Z.; Xu, B.; Yan, Y., Universal Dependence of Hydrogen Oxidation and Evolution Reaction Activity of Platinum-Group Metals on $\mathrm{pH}$ and Hydrogen Binding Energy. Sci. Adv. 2, e1501602 (2016).

12. Roger, I.; Symes, M. D., Silver leakage from Ag/ $\mathrm{AgCl}$ reference electrodes as a potential cause of interference in the electrocatalytic hydrogen evolution reaction. ACS Appl. Mater. Interfaces., 9 [1] $472-478$ (2016).

13. Lim, S. Y.; Ha, K.; Ha, H.; Lee, S. Y.; Jang, M. S.; Choi, M.; Chung, T. D., Three-dimensionally patterned Ag-Pt alloy catalyst on planar $\mathrm{Si}$ photocathodes for photoelectrochemical $\mathrm{H}_{2}$ evolution. Phys. Chem. Chem. Phys, 21 4184-4192 (2019).

14. Roen, L.; Paik, C.; Jarvi, T., Electrocatalytic Corrosion of Carbon Support in PEMFC Cathodes. Electrochem. Solid State Lett., 7 [1] A19-A22 (2004).

15. Castanheira, L.; Silva, W. O.; Lima, F. H.; Crisci, A.; Dubau, L.; Maillard, F. d. r., Carbon Corrosion in Proton-Exchange Membrane Fuel Cells: Effect of the Carbon Structure, the Degradation Protocol, and the Gas Atmosphere. ACS Catal., 5 [4] 2184-2194 (2015).

16. Choi, C. H.; Baldizzone, C.; Grote, J. P.; Schuppert, A. K.; Jaouen, F.; Mayrhofer, K. J., Stability of Fe-NC Catalysts in Acidic Medium Studied by Operando Spectroscopy. Angew. Chem., Int. Ed., 54 [43] 1275312757 (2015).

17. Lafforgue, C.; Maillard, F.; Martin, V.; Dubau, L.; Chatenet, M., Degradation of Carbon-Supported Platinum-Group-Metal Electrocatalysts in Alkaline Media Studied by in Situ Fourier Transform Infrared Spectroscopy and Identical-location Transmission 
Electron Microscopy. ACS Catal., 9 [6] 5613-5622 (2019).

18. Maillard, F.; Bonnefont, A.; Micoud, F., An EC-FTIR Study on the Catalytic Role of Pt in Carbon Corrosion. Electrochem. Commun., 13 [10] 11091111 (2011).

19. Ji, S. G.; Kim, H.; Park, C.; Kim, W.; Choi, C. H., Underestimation of Platinum Electrocatalysis Induced by Carbon Monoxide Evolved from Graphite Counter

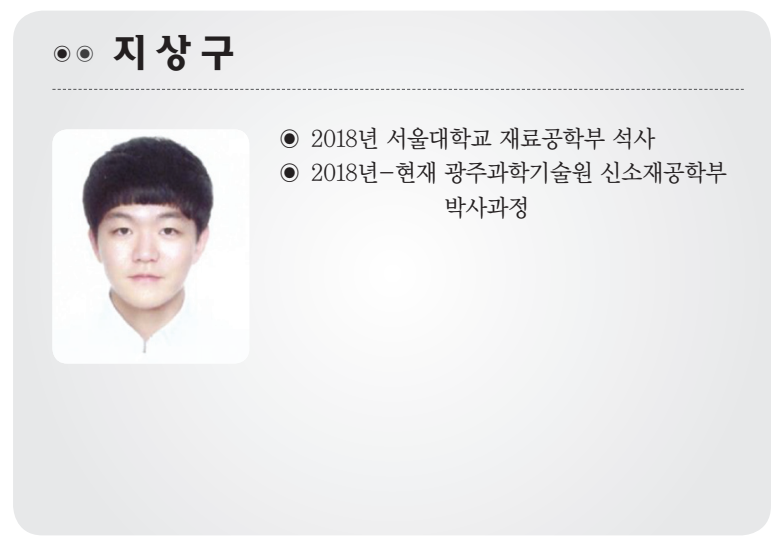

Electrodes. ACS Catalysis., 10 [18] 10773-10783 (2020).

20. Rudi, S.; Cui, C.; Gan, L.; Strasser, P., Comparative Study of the Electrocatalytically Active Surface Areas (ECSAs) of Pt Alloy Nanoparticles Evaluated by Hupd and CO-Stripping Voltammetry. Electrocatalysis., 5 408-418 (2014).

21. Martindale, B. Carbon caution. Nat Catal., 3 [773] (2020)

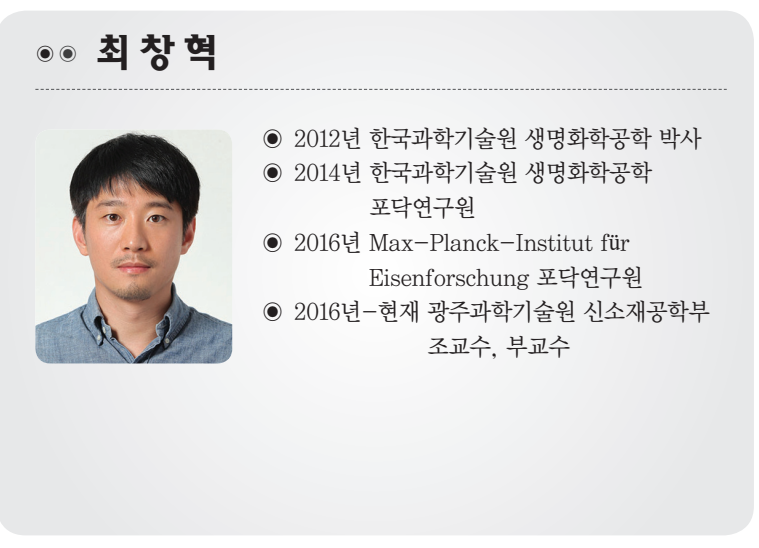

